\title{
Evaluation of Outcome of Treatment of Intertrochanteric Fracture with Dynamic Hip Screw (DHS)
}

\author{
Jonaed Hakim, ${ }^{1}$ Afrina Jahan, ${ }^{2}$ Mahbubur Rahman Khan, ${ }^{3}$ Md. Humayun Reza,${ }^{4}$ Rasel al Zilani, ${ }^{5}$ \\ Muhammad Shahiduzzaman, ${ }^{6}$ MKI Quayyum Choudhury ${ }^{7}$
}

\begin{abstract}
Background \& Objective: Intertrochanteric femur fractures are becoming increasingly common as our population ages. Effective treatment strategies that result in high rates of union of these fractures and low rates of complication are important. This study was designed to evaluate the clinical outcome of intertrochanteric fracture treated with dynamic hip screw, among many other fixation techniques available to fix intertrochanteric fractures.

Methods: This prospective interventional study was done in the Department of Orthopaedics \& Traumatology Department of Dhaka Medical College Hospital, Dhaka between June 2013 to November 2014. A total of 30 patients having intertrochanteric femur fracture were treated with Dynamic Hip Screw (DHS) after doing all necessary investigations for anesthetic fitness. Regular follow up was done up to six months after each operation and was observed for fracture healing, stability, complications and functional outcome by the prescribed scoring system (Harris Hip Score).
\end{abstract}

Result: Nearly one third $(30.0 \%)$ of the patients belonged to $7^{\text {th }}$ decade and male to female ratio was $1: 1.3$. According to Harris Hip Score, 13(44.82\%) patients were rated as excellent, $9(31.03 \%)$ good, 5(17.24\%) fair and 2(6.89\%) poor.

Conclusion: Dynamic hip screw (DHS) is a reliable method of fixing the stable intertrochanteric femur fractures. The reliability and long-term effect of dynamic hip screw used to treat intertrochanteric fractures of unstable variety are unsatisfactory and not up to the mark.

Key words:Hip Fractures, Infection, Dynamic Hip Screw, Fracture Fixation, Harris Hip Score

\section{INTRODUCTION:}

Intertrochanteric fractures of femur are still a big challenge in traumatology. The number of hip fractures is estimated to increase from 18,338 in 2010 to 50,421 in 2035 because of aging of the population. ${ }^{1}$ Intertrochanteric hip fractures represent almost half of all fractures of the proximal femur. ${ }^{2,3}$ Several factors may be associated with hip fracture incidence such as age, gender, and race/ethnicity. ${ }^{4}$ Intertrochanteric fractures occurring as consequences of either high-energy trauma is rare; mostly seen in young male patients, but simple low-energy falls are common and seen in elderly female patients. ${ }^{5} \mathrm{~A}$ truly stable intertrochanteric fracture is one, which when reduced, has a cortical contact without a gap medially and posteriorly. Whereas in unstable intertrochanteric fracture there is comminution of greater trochanter and there is no contact between proximal and distal fragment because of displaced posteromedial fragment. The importance of displaced lesser trochanter

\footnotetext{
Authors' information:

' Dr. Jonaed Hakim, Junior Consultant, Department of Orthopaedics \& Traumatology, BIRDEM (Bangladesh Institute of Research and Rehabilitation in Diabetes, Endocrine and Metabolic Disorders) General Hospital \& Ibrahim Medical College, 122 Kazi Nazrul Islam Avenue, Dhaka-1000, Bangladesh

${ }^{2}$ Dr. Afrina Jahan, Registrar, department of Orthopaedics \& Traumatology, BIRDEM (Bangladesh Institute of Research and Rehabilitation in Diabetes, Endocrine and Metabolic Disorders) General Hospital \& Ibrahim Medical College, 122 Kazi Nazrul Islam Avenue, Dhaka-1000, Bangladesh

${ }^{3}$ Dr. Mahbubur Rahman Khan, Junior Consultant, National Institute of Traumatology, Orthopaedics \& Rehabilitation (NITOR), Agargaon, Dhaka

${ }^{4}$ Dr. Md. Humayun Reza, MS (Orthosurgery) Assistant Professor, Orthosurgery, Sahid M. Mansur Ali Medical College, Sirajgonj

${ }^{5}$ Dr. Rasel al Zilani, Registrar, Kishoreganj Medical College, Kishoreganj

${ }^{6}$ Dr. Muhammad Shahiduzzaman, Professor \& Head, Department of Orthopaedics \& Traumatology, Dhaka Medical College, Dhaka
}

${ }^{7}$ Prof. MKI Quayyum Choudhury, Professor \& Head, Department of Orthopaedics \& Traumatology, BIRDEM General Hospital \& Ibrahim Medical College, Dhaka.

Correspondence: Dr. Jonaed Hakim, Phone: +880 1975701631 E-mail: hakimjonaed@gmail.com 
fragment, its size \& displacement are a key to decide the instability of intertrochanteric fracture. ${ }^{6}$

Non-surgical treatment of intertrochanteric hip fractures is usually reserved for patients with co-morbidities that place these patients at unacceptable risk from anesthesia, the surgical procedure, or both. ${ }^{7}$ When surgery is the choice of treatment for both stable and unstable intertrochanteric fractures, the surgical goal is to achieve and maintain a stable fracture reduction to allow early patient mobilization. Achieving this goal is dependent on a number of factors, including the fracture pattern, the stability of the reduction, and the method of fixation. The first group of implants to be used successfully was the fixed-angle nail plate devices, such as the Jewett nail. Although these devices provide fixation of the proximal fragment and fixation to the shaft, they do not allow fracture impaction. If impaction does not occur and there is lack of bone contact, increased loads on the device often resulted in either breakage of the device at the nail-plate junction or separation of the plate and screws from the shaft, particularly in unstable fractures. This gave rise to sliding nail-plate devices (Massie nail, Ken-Pugh nail), consisted of a nail that provided fixation in the proximal fragment and a side plate and barrel that allowed the nail to telescope within the barrel. This mechanism allowed controlled fracture impaction. Impaction provided bone-on-bone contact, which encouraged osseous healing and decreased the stress on the implant, thereby decreasing the incidence of implant failure. The sliding nail-plate devices were followed by the sliding screw-plate devices, in which the nail portion was replaced by a blunt-ended screw with a large outside-thread diameter. This modification resulted in improved proximal fragment fixation and decreased the possibility of cutting out superiorly by removing the sharp edges found on the nails. Today, the sliding hip screw, such as Dynamic Hip Screw is the device most commonly used for fixation of intertrochanteric fractures. ${ }^{7}$

In a developing country like Bangladesh, management of intertrochanteric fractures is based on individual patient factors, such as preinjury ambulatory status, age, comorbidities, the financial status of the patient, and on fracture factors, including fracture type and the degree of displacement and lastly the surgeon's skill to operate. Treating stable and unstable intertrochanteric fractures by dynamic hip screw (DHS) is the oldest method among many available options to manage such fractures. It had been applied in Dhaka Medical College Hospital for long. This study was aimed to evaluate the outcome of stable and unstable intertrochanteric fracture by Dynamic Hip Screw (DHS).

\section{METHODS:}

This study was done in Dhaka Medical College Hospital from June 2013 to May 2014. Prior permission was taken from Ethical Review Committee, Dhaka Medical College Hospital, Dhaka, Bangladesh to conduct the study. During the study period, 67 patients of intertrochanteric fractures were admitted in Dhaka Medical College Hospital, through emergency and out-patient Department (OPD). Patients older than 18 years having intertrochanteric fractures (Evan's Classification, modified by Jensen) treated with Dynamic Hip Screw (DHS) were enrolled in this study (Table:I). However, patients with pathological fractures, open fractures, intertrochanteric fractures with ipsilateral femoral shaft fractures were excluded from study. Of the 67 patients, 2 patients died due to diseases of old age before operation, 6 patients transferred to medicine unit for treatment of medical co-morbidities and not returned to orthopaedics, 3 patients were treated conservatively in the form of traction, 1 patient had open fracture, 3 patients were found to have pathological fracture, 1 patient had ipsilateral femoral shaft fracture and so 51 patients of intertrochanteric fracture were left to be treated operatively. Among these 51 patients, 8 patients were operated by Proximal Femoral Locking Plate (PFLP), 2 patients were operated by Dynamic Condylar Screw (DCS), 4 patients were treated with Proximal Femoral Nail (PFN) and 37 patients were treated with Dynamic Hip Screw (DHS). Among these 37 patients, 7 patients did not give consent for the study and 1 patient died on $3^{\text {rd }}$ post-operative day. So finally, the study was done on 29 patients. Informed written consent was taken from each patient before intervention. All the patients were evaluated by detail history, investigations like 
complete blood count, random blood sugar, serum creatinine, chest X-ray (PA view), ECG, blood grouping and cross matching, Echocardiogram (where available).

Following intervention and discharge from the hospital, regular follow up was done for each patient after operation to assess the functional outcome by the prescribed scoring system (Harris Hip Score). Six months follow up was targeted to evaluate the final functional outcome. Patients were followed up at out-patient department on 6 weeks ( $1^{\text {st }}$ follow up), 3 months ( $2^{\text {nd }}$ follow up) and 6 months after operation ( $3^{\text {rd }}$ follow up). All information was collected in a pre-designed structured data collection sheet. Statistical analysis was done by SPSS using descriptive statistics like frequency \& corresponding percentage.

\section{RESULTS:}

The mean age of the study subjects was 58.3 years. Males affected more frequently in 31-40 years age group ( $4: 1)$, whereas, females affected more often in 61-70 years (2:7) (Fig: 1 ). Out of 5 patients in age group $31-40$ years, $2(40 \%)$ had excellent outcome, $2(40 \%)$ good and $1(20 \%)$ fair outcome. Age group 41-50 years comprised of 5 patients. Of them $3(60 \%)$ had excellent, one $(20 \%)$ good and one $(20 \%)$ fair outcome. Age group 51-60 years comprised of 6 patients; 3(50\%) exhibited excellent and $3(50 \%)$ good outcome. Out of 8 patients in age group $61-70$ years, $3(37.5 \%)$ demonstrated excellent, 1(12.5) good, 2(25\%) fair and another $2(25 \%)$ poor outcome. Out of 3 patients in age group 71-80 years, 2(66.7\%) showed excellent result and $1(33.3 \%)$ good result. Two patients were above 80 years of age; of them $1(50 \%)$ showed good and $1(50 \%)$ fair result. These variations in results among age groups were statistically significant $(p>0.05)$ (Table: II).

Out of 29 cases, $2(6.9 \%)$ were type- 1 fracture, $7(24.1 \%)$ were type-2, another $7(24.1 \%)$ were type-3, 11(37.9\%) type- 4 and $2(6.9 \%)$ were type-5 fractures. Both of the two cases of type- 1 fractures demonstrated excellent result $(100 \%)$. Out of 7 cases of type-2 fractures, $5(71.4 \%)$ showed excellent and $2(28.5 \%)$ good result. Out of 7 type-3 fractures, $6(85.7 \%)$ had excellent and only $1(14.3 \%)$ had poor outcome. None of the 11 cases of type-4 fractures came out with excellent result, $7(63.6 \%)$ with good, $3(27.3 \%)$ with fair and only $1(9.09 \%)$ with poor result. Both of the two cases of type- 5 fractures had fair result (100\%) (Table III).

During the initial follow up almost all patients complained of mild to moderate pain. But at final follow up $13(44.8 \%)$ had painless hip, 9(31\%) complained of mild pain on walking for a distance, $5(17.2 \%)$ had moderate pain and needed analgesics to get relief of the pain. In $2(6.9 \%)$ patients, any bodily movement caused pain and they were on analgesics and rest (Table IV). Over half $(51.7 \%)$ of the patients regained unlimited walking ability, nearly one-quarter $(24.1 \%)$ needed one cane or walking stick (at the end of six months) to walk longer distance, $17.2 \%$ one crutch or stick and $6.9 \%$ two crutches or non-ambulatory (Table: $V$ ). Mean time from operation to sit in a chair was 3.26 days (range: 1 to 5 days). The rigid protocol of sitting in a chair or bedside on the $1^{\text {st }}$ postoperative day could not be followed in all cases. Some patients failed to do so on the $1^{\text {st }}$ postoperative day due to pain, headache and discomfort. Over half $(51.7 \%)$ of the patients could normally use climb stairs without using a railing, $7(24.1 \%)$ could climb stairs using a railing, 5(17.24\%) could climb stairs in any manners and $2(6.9 \%)$ were unable to climb stairs (Table VI). Out of 29 patients, $22(75.8 \%)$ regained full range of hip movements. $5(17.2 \%)$ had limited range of motion of the hip and in $2(6.9 \%)$ movements were restricted due to pain (Table VII).

So, in the final analysis of Harris Hip Score, $13(44.8 \%)$ patients were rated as excellent, $9(31.03 \%)$ patients were rated as good, $5(17.2 \%)$ as fair and $2(6.9 \%)$ as poor results. They were wheelchair bound and any movement of the hip caused pain. One of them had nonunion and lag screw cut out of the femoral head superiorly. Ultimately it ended up with varus angulation. Another developed deep infection and loosening of screws, so bed rest, antibiotic and analgesic were prescribed. All (100\%) of the stable (type $1 \& 2$ ) fractures had excellent or good result. Out of 20 cases of unstable fractures (type-3, 4, and 5) 
$13(65 \%)$ showed excellent or good result and 7 showed fair or poor result. This difference of result between stable $\&$ unstable fractures was significant $(p<0.001)$ (Figure 2).

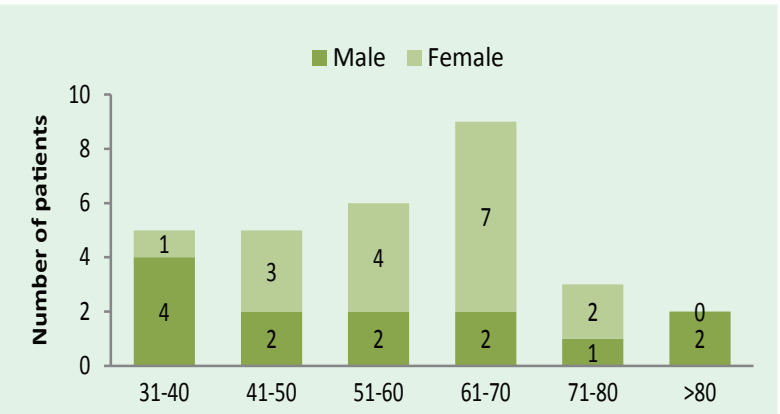

Figure-1: Age versus sex distribution of 30 patients

\begin{tabular}{|c|c|c|}
\hline Type of fracture & Frequency & Percentage \\
\hline \multicolumn{3}{|l|}{ Stable $(n=9)$} \\
\hline Type- 1 & 2 & 6.7 \\
\hline Type- 2 & 7 & 23.3 \\
\hline \multicolumn{3}{|l|}{ Unstable $(n=21)$} \\
\hline Type- 3 & 7 & 23.3 \\
\hline Type- 4 & 12 & 40.0 \\
\hline Type- 5 & 2 & 6.7 \\
\hline
\end{tabular}

Table II. Distribution of patients by age group and results $(n=29)$

\begin{tabular}{lccccc}
$\begin{array}{l}\text { Age group } \\
\text { (years) }\end{array}$ & \multicolumn{4}{c}{ Final Outcome } & p-value \\
\cline { 2 - 5 } & Excellent & Good & Fair & Poor & \\
$31-40$ & $2(40.0)$ & $2(40.0)$ & $1(20.0)$ & $0(0.0)$ & \\
$41-50$ & $3(60.0)$ & $1(20.0)$ & $1(20.0)$ & $0(0.0)$ & \\
$51-60$ & $3(50.0)$ & $3(50.0)$ & $0(0.0)$ & $0(0.0)$ & 0.05 \\
$61-70$ & $3(37.5)$ & $1(12.5)$ & $2(25.0)$ & $2(25.0)$ & \\
$71-80$ & $2(66.7)$ & $1(33.3)$ & $0(0.0)$ & $0(0.0)$ & \\
$>80$ & $0(0.0)$ & $1(50.0)$ & $1(50.0)$ & $0(0.0)$ &
\end{tabular}

Table III. Distribution of cases by fracture types and results $(n=29)$

\begin{tabular}{lcccc}
\hline \multirow{4}{*}{$\begin{array}{l}\text { Fracture } \\
\text { types }\end{array}$} & \multicolumn{4}{c}{ Results } \\
\cline { 2 - 5 } Excellent & Good & Fair & Poor \\
\hline Type- 1 & $2(100)$ & $0(0.0)$ & $0(0.0)$ & $0(0.0)$ \\
Type- 2 & $5(71.5)$ & $2(28.5)$ & $0(0.0)$ & $0(0.0)$ \\
Type-3 & $6(85.7)$ & $0(0.0)$ & $0(0.0)$ & $1(14.3)$ \\
Type- 4 & $0(0.0)$ & $7(63.7)$ & $3(27.3)$ & $1(9.0)$ \\
Type- 5 & $0(0.0)$ & $0(0.0)$ & $2(100.0)$ & $0(0.0)$
\end{tabular}

Table IV. Distribution of patients by criteria of pain $(n=29)$

\begin{tabular}{|c|c|c|}
\hline Criteria of pain & Frequency & Percentage \\
\hline $\begin{array}{l}\text { Free of pain/ Occasional pain, } \\
\text { but no compromise of activity }\end{array}$ & 13 & 44.8 \\
\hline Mild pain & 9 & 31.0 \\
\hline Moderate pain & 5 & 17.2 \\
\hline $\begin{array}{l}\text { Serious pain causing limitation } \\
\text { of activity/ Pain in any motion }\end{array}$ & 2 & 6.9 \\
\hline
\end{tabular}

Table V. Distribution of patients by walking ability (Support)

$\begin{array}{lcc}\text { Walkingability (Support) } & \text { Frequency } & \text { Percentage } \\ \begin{array}{l}\text { Regained previous walking ability / } \\ \text { No support needed }\end{array} & 15 & 51.7 \\ \begin{array}{l}\text { One cane or walking stick for long } \\ \text { work and most of the time }\end{array} & 7 & 24.2 \\ \text { Walk with crutches / walking stick } & 5 & 17.2 \\ \text { Two crutches / Non-ambulatory } & 2 & 6.9\end{array}$

Table VI. Distribution of patients by climbing stairs $(\mathbf{n}=29)$

\begin{tabular}{lcc}
\hline Climbingstairs & Frequency & Percentage \\
\hline Normally without using rallying & 15 & 51.7 \\
Normally using a rallying & 7 & 24.2 \\
In any manner & 5 & 17.2 \\
Unable to use stairs & 2 & 6.9
\end{tabular}

\section{Table VII. Distribution of patients by hip mobility ( $\mathbf{n = 2 9 )}$}

$\begin{array}{lcc}\text { Mobility of hip } & \text { Frequency } & \text { Percentage } \\ \text { Full range of motion } & 22 & 75.8 \\ \text { Limited range of motion } & 5 & 17.2 \\ \text { Movements not possible due to pain } & 2 & 6.9\end{array}$

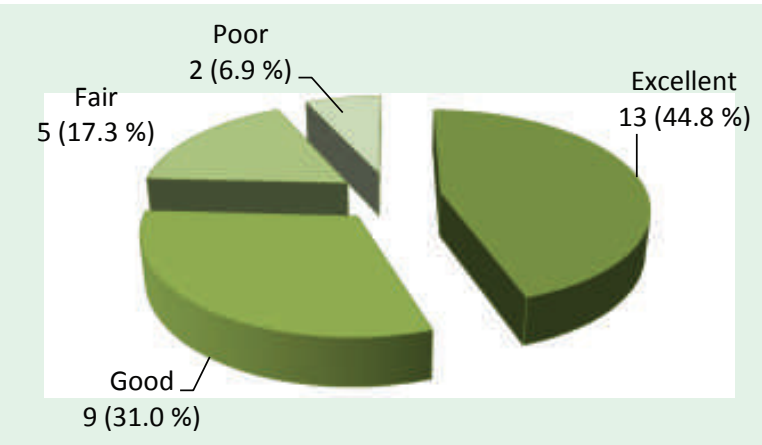

Figure 2: Pie chart shows final result of the study patients

\section{DISCUSSION:}

Achieving the goal for two parts stable intertrochanteric fracture is no longer a problem now-a-days. For 
unstable comminuted intertrochanteric fracture, it remains a challenging but common problem. ${ }^{8,9}$ This series included 30 cases of intertrochanteric fractures in adult and elderly; out of them, one diabetic patient died on $3^{\text {rd }}$ postoperative day in BIRDEM General Hospital. Remaining 29 patients were evaluated with a follow up of 6 months. The outcome was satisfactory (good to excellent) in more than $75 \%$, cases. The result is comparable to that of the study reported by Adams et $\mathrm{al}^{10}$, where the average Harris Hip Score at 6 months of follow up was 66.4, though they did not categorize the patients based on the Harris Hip Score. Stable intertrochanteric fractures are commonly treated with dynamic hip screw fixation with failure rate of less than $2 \%$. The treatment of unstable intertrochanteric fractures is more controversial. Unstable intertrochanteric fractures treated with Dynamic Hip Screw have considerable failure rate, ranging from 4 to $15 \% .{ }^{11}$

The average operation time in the present study was longer than that of Setiobudi et $\mathrm{a}^{11}$ study (mean operation time $58 \pm 18$ minutes) for 61 stable intertrochanteric fractures. Another study by Adams et $\mathrm{al}^{10}$, showed average operation time of 61.3 minutes (58.2-64.4 minutes) in 197 patients operated with Dynamic Hip Screw. In the present series, in $1(3.4 \%)$ case only, the lag screw was cut out of the femoral head with varus angulation and resulted in nonunion. This case was considered as mechanical failure. Satisfactory radiological healing with acceptable alignment occurred in the remaining $28(95.5 \%)$ cases.

Full range of painless hip movement is a prerequisite for leading a normal life. Out of 29 patients, $2(6.89 \%)$ patients had pain while having any motion. In one it was due to lag screw cutout of the femoral head and in another due to deep infection. Another $5(17.2 \%)$ patients had moderate pain and limited range of hip mobility and needed crutch support for walking, $17(58.6 \%)$ could wear their shocks and shoes with ease. Nearly $45 \%$ patients had no or minimum limp, $48.3 \%$ had noticeable limp and $6.9 \%$ were unable to bear any weight on the operated limb. Over $75 \%$ were reported to walk with crutch with partial weight bearing. In walking frame within 3 months, 2 of these cases were type 4 and 2 were type 5 unstable fracture. Among the remaining $3(10.3 \%)$ patients, 1 had bilateral Colle's fracture, 1 had contralateral ankle injury and in 1, fixation of the fracture was not satisfactory. So these patients were allowed partial weight bearing 8 weeks after operation. Full weight bearing in 3 months was observed in 28 patients. Full weight bearing was never possible in one patient due to pain and unacceptable radiological healing and position of lag screw. Finally, at the end of six months, $7(24.1 \%)$ patients needed one cane for walking and 2(6.9\%) were non-ambulatory. Among them, 1 patient had unacceptable radiological healing and nail position in femoral head, so failed to bear weight. Another patient, though walked full weight bearing in 3 months, could not continue it due to pain and deep infection was suspected. They had no definite cause but probably it may occur due to contracture of hip capsule and surrounding musculature as a consequence of delayed and prolonged surgery.

So, in the final analysis of Harris Hip Score, $13(44.8 \%)$ patients were rated as excellent. They regained excellent range of motions and restored normal functional and walking ability without any limp and pain. They needed no support for walking. Radiologically, there were bony unions in good alignment and all of them were satisfied with operative treatment and returned to their previous job. Nine $(31.0 \%)$ patients were rated as good. All of them regained full range of motion. They had occasional mild pain and noticeable limp. They used a cane for walking. Radiologically the union was good and alignment was acceptable. Five (17.2\%) patients were rated as fair. They had a limited range of motion, moderate pain, needed analgesic with noticeable limp and needed crutches for walking. But their radiological union was sound. Two patients were rated as poor and they were wheelchair bound and any movement of the hip caused pain. ${ }^{12,13}$

Wound infection occurred in $5(16.6 \%)$ patients, among them $3(10 \%)$ had just stitch infection and $2(6.6 \%)$ had deep infection. Causative organism was Staphylococcus aureus in all cases and it was found sensitive to both flucloxacillin and clauvulonic acid. Stitch infection was controlled within 5 days of antibiotic therapy, but the antibiotic was continued 
up to 2 weeks. The deep infection was managed by open drainage and secondary closure associated with antibiotic therapy for 3 weeks.

The study population was selected from the Department of Orthopaedics \& Traumatology, Dhaka Medical College \& Hospital, Dhaka and therefore, lacks generalization. The operating surgeons were not the same in all cases which might have resulted in operator dependent variation in outcome to some extent. The purposive sampling was used in selecting study population and the entire sample was collected from the patients operated after admission. This sampling bias further limits the generalization of the findings.

\section{CONCLUSION:}

From the findings, it can be concluded that, Dynamic Hip Screw is a reliable and standard method of fixing the stable intertrochanteric femur fractures. In case of fixing the unstable intertrochanteric femur fractures with Dynamic Hip Screw, its reliability and long-term effect are unsatisfactory and not up to the mark.

\section{REFERENCES:}

1. Chen IJ, Chiang CY, Li YH, Chang CH, Hu CC, Chen DW, Chang Y, Yang WE, Shih HN, Ueng SW, Hsieh PH. Nationwide cohort study of hip fractures: time trends in the incidence rates and projections up to 2035. Osteoporos Int 2015;26(2):681-88. doi: 10.1007/ s00198 -014-2930-z.

2. Koval KJ, Zuckerman JD. Hip Fractures: II. Evaluation and Treatment of Intertrochanteric Fractures. J Am Acad Orthop Surg 1994;2(3):150-156.

3. Cooper C, Campion G, Melton LJ $3^{\text {rd }}$. Hip fractures in the elderly: a world-wide projection. Osteoporos Int 1992;2 (6):285-9.

4. Brauer CA, Coca-Perraillon M, Cutler DM, Rosen AB. Incidence and mortality of hip fractures in the United States. JAMA 2009;302(14):1573-79. doi: 10.1001/jama. 2009.1462.

5. Dhanwal DK, Dennison EM, Harvey NC, Cooper C. Epidemiology of hip fracture: Worldwide geographic variation. Indian $\mathrm{J}$ Orthop 2011;45(1):15-22. doi: 10.4103/0019-5413.73656.

6. Babhulkar, SS. Management of trochanteric fractures. Indian Journal of Orthopaedic, 2006;40(4):210-218.
7. Kaplan K, Miyamoto R, Levine BR, Egol KA, Zuckerman JD. Surgical management of hip fractures: an evidence-based review of the literature. II: intertrochanteric fractures. J Am Acad Orthop Surg 2008;16(11):665-73.

8. Medoff RJ, Maes K. A new device for the fixation of unstable pertrochanteric fractures of the hip. J Bone Joint Surg Am 1991;73(8):1192-99.

9. Larsson S, Friberg S, Hansson LI. Trochanteric fractures. Mobility, complications, and mortality in 607 cases treated with the sliding-screw technique. Clin Orthop Relat Res $1990 ;(260): 232-41$.

10. Adams CI, Robinson CM, Court-Brown CM, McQueen MM. Prospective randomized controlled trial of an intramedullary nail versus dynamic screw and plate for intertrochanteric fractures of the femur. J Orthop Trauma 2001;15(6):394-400.

11. Setiobudi $\mathrm{T}, \mathrm{Ng} \mathrm{YH}$, Lim CT, Liang S, Lee K, Das De S. Clinical outcome following treatment of stable and unstable intertrochanteric fractures with dynamic hip screw. Ann Acad Med Singapore 2011;40(11):482-7.

12. Peyser A, Weil $Y A$, Brocke $L$, Sela $Y$, Mosheiff $R$, Mattan $Y$, Manor O, Liebergall M. A prospective, randomised study comparing the percutaneous compression plate and the compression hip screw for the treatment of intertrochanteric fractures of the hip. J Bone Joint Surg $\mathrm{Br}$ 2007;89(9):1210-17.

13. Whitelaw GP, Segal D, Sanzone CF, Ober NS, Hadley N. Unstable intertrochanteric/subtrochanteric fractures of the femur. Clin Orthop Relat Res 1990;(252):238-45. 